\title{
DESENVOLVIMENTO DE JOGOS EDUCACIONAIS NO APOIO DO PROCESSO DE ENSINO- APRENDIZAGEM NO ENSINO FUNDAMENTAL
}

\author{
I. K. O. SILVA', M. J. O. MORAIS II \\ ${ }^{1}$ Instituto Federal de Educação, Ciência e Tecnologia do Rio Grande do Norte - Campus Caicó \\ isayane_2010@hotmail.com - marcal.morais@ifrn.edu.br
}

Artigo submetido em Outubro/2011 e aceito em dezembro/2011

\section{RESUMO}

Desde a Antiguidade vem sendo pesquisadas formas variadas para tornar o processo ensinoaprendizagem mais satisfatório tanto para os alunos quanto para os professores. Durante muitos anos o computador era um equipamento caro e de difícil acesso a pessoas mais carentes, mas após um projeto lançado por uma universidade dos Estados Unidos, o Brasil iniciou o projeto "Um Computador por Aluno" (UCA), que tem como objetivo facilitar o acesso à informação e à aprendizagem dos alunos de escolas públicas por meio de netbooks educacionais de baixo custo. Tendo em vista a possibilidade de utilização dos netbooks no apoio ao processo de ensino-aprendizagem dos alunos em todas as disciplinas do ensino fundamental, este trabalho teve como objetivo o desenvolvimento de jogos educacionais que facilitassem de forma interativa a aprendizagem de diversos conceitos estudados em sala de aula. Os jogos desenvolvidos são totalmente adaptados aos netbooks do projeto UCA e foram testados em uma escola estadual contemplada com os computadores do projeto, a qual tiveram seus professores como colaboradores no planejamento didático dos jogos. Após a utilização dos jogos, foram realizados testes que constataram um aumento significativo no nível de conhecimento dos alunos.

PALAVRAS-CHAVE: Aprendizagem dos alunos, jogos educacionais, Projeto UCA.

\section{DEVELOPMENT OF EDUCATIONAL GAMES IN SUPPORT OF THE TEACHING-LEARNING PROCESS IN THE ELEMENTARY SCHOOL}

\section{ABSTRACT}

Since ancient times has been studied many forms to make the teaching-learning process more satisfying for both the students and for teachers. For many years the computer equipment was an expensive and difficult to reach the poorest people, but after a project launched by a U.S.A university, Brazil started the project One computer per student (UCA), which aims to facilitate access to information and learning of students in public schools through educational netbooks at low cost. Given the possibility of using netbooks to support the process of teaching and learning of students in all disciplines of basic education, this study aimed to develop educational games that interactively facilitate the learning of various concepts studied in room class. The games developed are fully adapted to the low cost laptops and netbooks were tested in a state school with computers included in the project, which had their teachers as collaborators in the planning of educational games. After the use of games, tests were performed that demonstrated a significant increase in the level of knowledge of students.

KEY-WORDS: student's learning, Educational games, UCA project. 


\section{DESENVOLVIMENTO DE JOGOS EDUCACIONAIS NO APOIO DO PROCESSO DE ENSINO- APRENDIZAGEM NO ENSINO FUNDAMENTAL}

\section{INTRODUÇÃO}

A educação é como uma herança a que se busca aprimorar para fazê-la render bons resultados. Desde o tempo escravocrata, administramos uma educação de baixíssima qualidade para a população em geral, privilegiando apenas uma pequena parte desse público com o direito de conseguir tal educação de forma satisfatória. Isso deixou como sequela uma sociedade que continua desenvolvendo diversas formas de discriminação, inclusive na educação.

Desde a Antiguidade, vem sendo pesquisadas formas variadas para tornar o processo de ensino-aprendizagem mais satisfatório tanto para os alunos quanto para os professores. Na busca por esses avanços surgem os computadores, que inicialmente aparecem como máquinas que tem como principal objetivo transformar dados em informações. Tais máquinas conquistaram um enorme espaço em bancos, empresas, indústrias, dentre outros, e hoje adentram nas escolas para melhorar e colaborar com uma educação de qualidade para os alunos. Hoje vemos um mundo cada vez mais voltado para a tecnologia, e tais tecnologias atuam nas mais diversas áreas, como no celular ou nas escolas demonstrando uma maneira lúdica, divertida e prazerosa de se ver ou conduzir uma aula.

Buscando aumentar o acesso à informação, o Brasil aderiu, em 2005, a um projeto internacional chamado "Um Computador por Aluno" (UCA), que tem como objetivo distribuir netbooks para as escolas públicas brasileiras. Esses netbooks possuem alguns softwares educacionais, que tem por objetivo facilitar a compreensão dos alunos auxiliando os professores no processo de ensinoaprendizagem.

Existem atualmente diversos tipos de softwares educacionais, e dentre eles estão os jogos educacionais que se apresentam como uma ótima ferramenta para a educação, pois apresentam um grande valor pedagógico, além de prender a atenção do aluno e possibilitar que ele aprenda através de suas próprias interações com o jogo.

Segundo Orso apud Grübel (2006) "a criança precisa ser alguém que joga para que, mais tarde, saiba ser alguém que age, convivendo sadiamente com as regras do jogo da vida. Saber ganhar e perder deveria acompanhar a todos sempre". Com a utilização dos jogos, os alunos desenvolvem capacidades, habilidades, conhecimentos e atitudes, além de auxiliar na construção da sua autoconfiança.

Como o processo de aprendizagem dos diversos conteúdos transmitidos em sala de aula está ficando cada vez mais difícil tanto para os alunos que assistem às aulas teóricas com pouca ou nenhuma contextualização, quanto para os professores que se sentem impotentes diante de tal problema, este artigo tem o intuito de facilitar a aprendizagem dos conteúdos programados para o ensino fundamental, favorecendo o desenvolvimento cognitivo do aluno e criando estratégias para a solução dos problemas propostos pelo professor, através da utilização de jogos educacionais que vem se tornando um excelente recurso didático no auxílio à aprendizagem dos alunos, colaborando para o seu desenvolvimento e motivando o aluno a experimentar situações que não são permitidas na realidade. 


\section{A EDUCAÇÃO E OS JOGOS EDUCACIONAIS}

Durante muitos anos os alunos eram considerados sujeitos passivos em sala de aula, cabendo ao mesmo apenas receber as informações que lhes eram transmitidas pelo professor, o qual tinha papel principal no processo ensino-aprendizagem (DEWEY, 2000). Com o passar do tempo, os alunos começaram a ganhar mais autonomia em sala de aula, tornando-se mais independentes, o que os fez transitarem de sujeito passivo para ativo, participando ativamente das aulas, fazendo com que o professor continue sempre buscando resgatar o interesse do educando pelo ensino procurando criar condições ideais para que os alunos dominem os conteúdos abordados em sala, uma vez que os mesmos não se encontram mais satisfeitos com livros didáticos, quadro negro e giz.

Deste modo, foram surgindo inúmeros métodos de ensino com diferentes estratégias para que os professores pudessem construir uma ponte que ligasse o aluno ao conteúdo didático, diminuindo, assim, os altos níveis de reprovação e o baixo desempenho dos mesmos. Algumas estratégias são descritas por Libâneo (1994):

- Método de exposição pelo professor, onde os conhecimentos e habilidades são apresentados pelo professor podendo ser expostos através de exposição verbal, demonstração, ilustração e exemplificação;

- Método de trabalho independente, onde o professor aplica tarefas para serem resolvidas pelos alunos, porém dirigidas e orientadas por ele;

- Método de elaboração conjunta, na qual o professor utiliza sua experiência e seus conhecimentos para aproximar gradativamente os alunos da organização lógica dos conhecimentos e a dominar métodos de elaboração das ideias independentes;

- Método de trabalho em grupo, ao qual consiste em distribuir temas de estudo iguais ou diferentes a grupos fixos ou variáveis de alunos, e que para serem bem sucedidos é fundamental que haja uma ligação orgânica entre a fase de preparação, a organização dos conteúdos e a comunicação dos seus resultados para a turma, como exemplos podemos citar o debate, grupo de verbalização, seminários dentre outros;

- Atividades Especiais, as quais complementam e assimilam os conteúdos estudados, como exemplo temos o estudo do meio, planejamento, execução e exploração dos resultados e avaliação.

Com base nesta perspectiva, os jogos educacionais ajustam-se perfeitamente à estratégia das "Atividades Especiais", uma vez que os mesmos possibilitam aos alunos uma consolidação satisfatória dos conteúdos ministrados em sala de aula, o que pode ser revalidado por meio de avaliações realizadas antes e depois da utilização dos jogos.

Escuta-se falar em ligar a teoria à prática, mas como fazer isso realmente acontecer nas salas de aula? Surgindo também como uma estratégia de ensino, os jogos educacionais nos propiciam a 
experimentar situações não permitidas na realidade. Desta forma, os jogos educacionais, sendo eles computacionais ou não, desenvolvem papel fundamental no processo de aprendizagem dos alunos, uma vez que são utilizados para auxiliá-los na criação de estratégias para a solução de problemas. Freire apud Lopes e Wilhelm (2006), afirma que "ensinar não é transferir conhecimento, mas criar possibilidades para a sua própria produção ou sua construção". Diferentes dos demais jogos utilizados pela maioria dos jovens de hoje, os jogos educacionais atuam como um recurso didático na construção do conhecimento, motivando e desafiando os alunos, divertindo e ensinando ao mesmo tempo, agregando o lazer e a diversão, tornando o aluno autor ou coautor do seu próprio conhecimento.

Cada jogo possui seus próprios benefícios e características, explorando de forma gradativa diversos aspectos, com isso os alunos despertam a perspectiva de atingir o objetivo proposto no jogo gerando um aumento cognitivo. Além disso, por meio do jogo a vida social e as necessidades intelectuais e afetivas do indivíduo também são desenvolvidas, o que favorece não só o aprendizado, mas também habilidades e atitudes éticas.

A inserção de jogos, segundo Grando (2001), no contexto de ensino-aprendizagem implica em vantagens e desvantagens:

\begin{tabular}{|c|c|}
\hline VANTAGENS & DESVANTAGENS \\
\hline $\begin{array}{l}\text { - Fixação de conceitos já aprendidos de uma forma } \\
\text { motivadora para o aluno; } \\
\text { - Introdução e desenvolvimento de conceitos de difícil } \\
\text { compreensão; } \\
\text { - Desenvolvimento de estratégias de resolução de } \\
\text { problemas (desafio dos jogos); } \\
\text { - Aprender a tomar decisões e saber avaliá-las; } \\
\text { - Significação para conceitos aparentemente } \\
\text { incompreensíveis; } \\
\text { - Propicia o relacionamento das diferentes disciplinas } \\
\text { (interdisciplinaridade); } \\
\text { - O jogo requer participação ativa do aluno na construção } \\
\text { do seu próprio conhecimento; } \\
\text { - O jogo favorece a socialização entre alunos e a } \\
\text { conscientização do trabalho em equipe; } \\
\text { - A utilização dos jogos é um fator de motivação para os } \\
\text { alunos; } \\
\text { - Dentre outras coisas, os jogos favorecem o } \\
\text { desenvolvimento da criatividade, do senso crítico, da } \\
\text { participação, da competição "sadia", da observação, das } \\
\text { várias formas de uso da linguagem e do resgate do prazer } \\
\text { em aprender; } \\
\text { - As atividades com jogos podem ser utilizadas para } \\
\text { reforçar ou recuperar habilidades de que alunos } \\
\text { necessitem. Útil no trabalho com alunos de diferentes } \\
\text { níveis; } \\
\text { - As atividades com jogos permitem ao professor } \\
\text { identificar, diagnosticar alguns erros de aprendizagem, as } \\
\text { atitudes e as dificuldades dos alunos. }\end{array}$ & $\begin{array}{l}\text { - Quando os jogos são mal utilizados, existe o perigo de } \\
\text { dar ao jogo um caráter puramente aleatório, tornando-se } \\
\text { um "apêndice" em sala de aula. Os alunos jogam e se } \\
\text { sentem motivados apenas pelo jogo, sem saber porque } \\
\text { jogam; } \\
\text { - O tempo gasto com atividades de jogo em sala de aula é } \\
\text { maior e, se o professor não estiver preparado, pode } \\
\text { existir um sacrifício de outros conteúdos pela falta de } \\
\text { tempo; } \\
\text { - As falsas concepções que se devem ensinar todos os } \\
\text { conceitos através de jogos. Então as aulas, em geral, } \\
\text { transformam-se em verdadeiros cassinos, também sem } \\
\text { sentido algum para o aluno; } \\
\text { - A perda da "ludicidade" do jogo pela interferência } \\
\text { constante do professor, destruindo a essência do jogo; } \\
\text { - A coerção do professor, exigindo que o aluno jogue, } \\
\text { mesmo que ele não queira, destruindo a voluntariedade } \\
\text { pertencente à natureza do jogo; } \\
\text { - A dificuldade de acesso e disponibilidade de material } \\
\text { sobre o uso dos jogos no ensino, que possam vir a } \\
\text { subsidiar o trabalho docente. }\end{array}$ \\
\hline
\end{tabular}

Quadro 1: Vantagens e desvantagens dos jogos educacionais (GRANDO, 2001)

Assim, os jogos não podem ser considerados apenas diversão, e sim uma necessidade que todo ser humano independente da idade possui, podendo sofrer modificações na sua metodologia, 
procedimentos e estratégias, variando de acordo com as necessidades específicas dos alunos e sua faixa etária.

O jogo é um fenômeno antropológico que se deve considerar no estudo do ser humano. É uma constante em todas as civilizações, esteve sempre unido à cultura dos povos, à sua história, ao mágico, ao sagrado, ao amor, à arte, à língua, à literatura, aos costumes, à guerra. $O$ jogo serviu de vínculo entre povos, é um facilitador da comunicação entre os seres humanos (MURCIA, 2005, p. 09).

Os jogos possuem um valor educacional intrínseco, pois age como um motivador, unindo a vontade e o prazer durante o desenvolvimento de uma atividade, tornando as aulas agradáveis e a aprendizagem fascinante, pois o ato de aprender associa-se à diversão. No entanto, três pilares são fundamentais para o sucesso na utilização dos jogos nas escolas: educadores preparados, estrutura escolar e planejamento adequado, além de boa variedade e qualidade de jogos à disposição. Sem esses pilares, a experiência educacional com o uso de jogos pode gerar resultados frustrantes.

Contudo, a pretensão da maioria dos professores com a utilização dos jogos é transformar as atividades desenvolvidas em situações que estimulem o raciocínio, levando o aluno a enfrentar situações conflitantes relacionadas com o seu cotidiano.

\section{OS JOGOS COMPUTACIONAIS}

O uso das novas tecnologias em sala de aula não é uma ideia tão nova assim, há muitos anos autores e professores visavam colocar o computador como instrumento de ensino para aumentar a capacidade de aprendizagem dos educandos para além da realidade física da escola. Os jogos são softwares de entretenimento e sua popularidade se deve aos desafios propostos que incitam os jogadores a jogarem cada vez mais até chegarem ao objetivo final do jogo. A utilização desses softwares na educação auxilia o aluno a desenvolver hábitos de persistência para que o aluno sinta-se motivado a vencer os desafios e as tarefas propostas no jogo:

[...] por muitos anos os jogos têm sido usados apenas para diversão, mas só recentemente têm sido aplicados os elementos estratégicos de jogos em computadores com propósitos instrutivos (LERNER, 1991, p.59).

A busca intensa por recursos didáticos que aumentem as possibilidades de aprendizagem dos alunos mostram os jogos como um excelente apoio pedagógico para professores e alunos, possibilitando a expressão de sentimentos e demonstrando situações presentes no cotidiano dos discentes. Seabra (1993) afirma que os jogos bem feitos podem se tornar uma interessante ferramenta didática nas mãos de um professor, criando um ambiente lúdico que pode ser a base para uma abordagem diferenciada da matéria.

Esse ambiente lúdico emprega-se utilmente ao uso de jogos computacionais, tornando o 
processo ensino-aprendizagem mais satisfatório, propondo desafios que divertem enquanto ensinam, desenvolvendo habilidades funcionais e contribuindo também para uma boa saúde mental, uma vez que melhoram a flexibilidade cognitiva, funcionando como uma ginástica mental, aumentando a rede de conexões neurais e alterando o fluxo sanguíneo no cérebro quando em estado de concentração.

Desta maneira, ao construir mentalmente a estrutura do jogo, o aprendiz forma seu próprio "micro mundo", construindo estratégias mentais que desencadeiam o raciocínio. Assim, é indiscutível o uso de jogos como material didático, pois propiciam a utilização das diversas linguagens e representações geométricas, além de motivar e incentivar a criatividade dos aprendizes. Esta é, sem dúvida, a área da informática que ganhou mais terreno nos últimos anos, mostrando que é possível a criação de ambientes de ensino adaptado às características de cada aluno, somando as vantagens que os jogos trazem consigo: entusiasmo, concentração, motivação, entre outros.

\section{PROJETO UM COMPUTADOR POR ALUNO (UCA)}

O projeto "Um Computador por Aluno" (UCA) surgiu a partir de um projeto desenvolvido pelo MIT (Instituto de Tecnologia de Massachusetts), que tinha como objetivo desenvolver computadores de baixo custo para serem utilizados na educação como facilitador do processo de ensinoaprendizagem em sala de aula (GINGER, 2009). Posteriormente, a ONG internacional One Laptop Per Child (OLPC) foi criada com a intenção de divulgar o projeto nos principais países em desenvolvimento, entre eles o Brasil.

O projeto UCA consiste em distribuir netbooks para alunos de escolas públicas no Brasil, com a intenção de melhorar a qualidade do ensino e promover a inclusão digital, dando, assim, mais oportunidades aos seus alunos (MALFATTI et al, 2010). Além da distribuição do netbooks, a escola também receberá toda a infraestrutura para oferecer acesso à internet aos alunos.

O projeto UCA teve início em 2005, no Brasil, após a visita do representante oficial da ONG OLPC. Na ocasião, firmou-se uma parceria com o Governo Federal. Após a parceria realizada, o governo iniciou o processo de aquisição e distribuição dos netbooks. Em seguida, o processo de distribuição foi dividido em etapas. Inicialmente, apenas algumas escolas receberam os computadores, onde foi analisado efetivamente a melhoria do ensino em sala de aula. Após o processo inicial, a distribuição dos netbooks aos poucos vem atingindo todo o país.

Apesar de o projeto inicial prever a utilização dos equipamentos dentro e fora da escola, atualmente só é permitido ao aluno a utilização durante o período em que estiver na escola. Contudo, visto que grande parte da população brasileira não possui acesso ao uso de computadores, e muito menos da internet, a utilização desses netbooks na escola representa um grande avanço na educação brasileira, possibilitando além da inclusão digital dos alunos, a oportunidade de utilização de uma ferramenta que, se bem utilizada, torna-se muito importante no aprendizado dos mesmos.

\section{JOGOS ELETRÔNICOS PARA O PROJETO UCA}

Apesar de existirem diversos jogos educacionais proprietários e gratuitos, em sua maioria eles não se adaptam ao netbook do projeto UCA devido aos seus recursos limitados como, por exemplo, 
sua tela, memória e processamento. Devido ao pouco tempo de implantação do projeto UCA, pouco tem sido feito em relação a jogos educacionais para este netbook. Contudo, após pesquisa realizada, encontramos alguns jogos disponíveis desenvolvidos por um grupo de pesquisa da Universidade Católica de Tocatins (MALFATTI et al, 2010). Alguns dos softwares desenvolvidos são mostrados a seguir.

A Tabuada Espacial trata-se de um jogo que possui uma mira onde o aluno deve acertar o resultado de uma operação matemática que aparece no canto inferior da tela e a cada tiro correto o aluno irá acumular pontos. A imagem a seguir demonstra o jogo Tabuada Espacial.

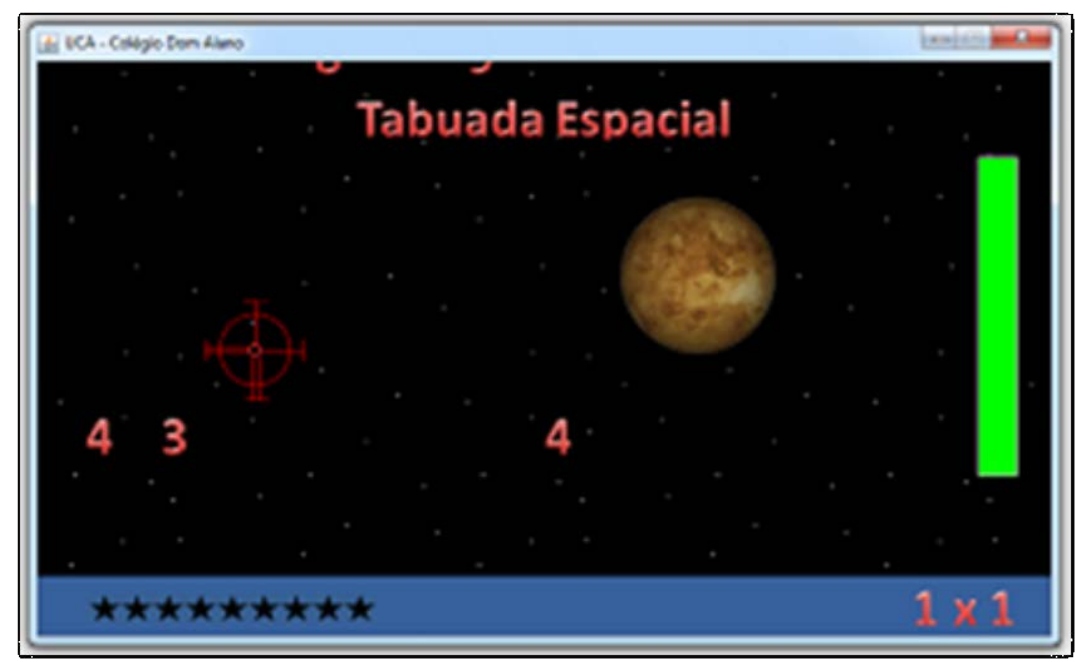

Figura 1: Jogo Tabuada Espacial

Outro jogo desenvolvido pelo grupo é o jogo Super Contas, que é bastante simplificado. Nele, o aluno deve responder qual o operador matemático que deverá ser utilizado para se obter o resultado demonstrado. A imagem a seguir demonstra o jogo Super Contas.

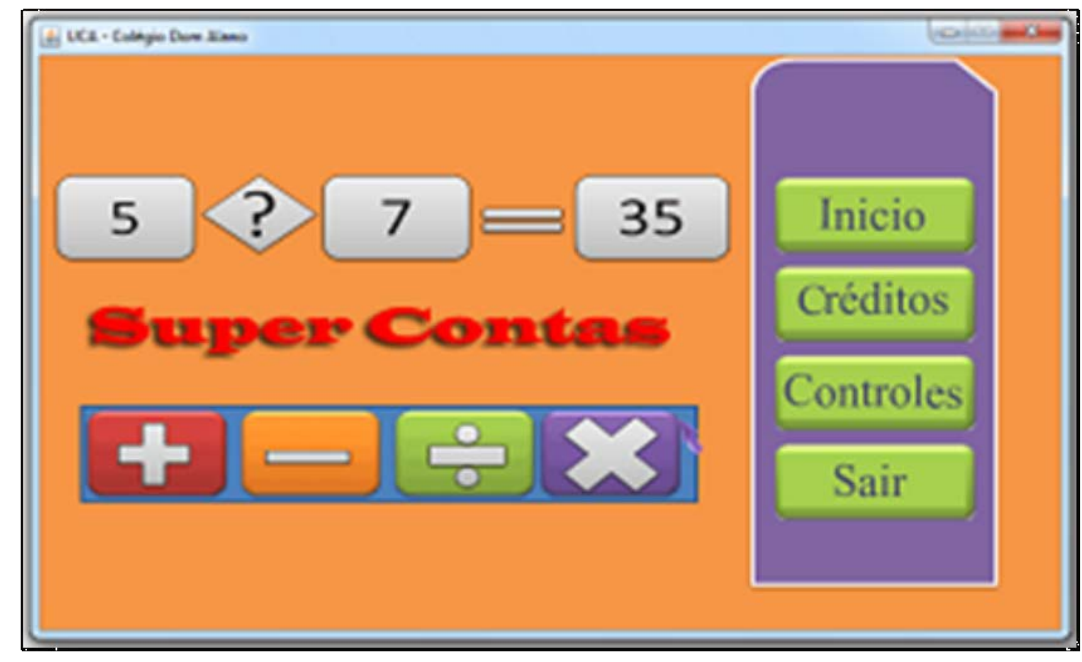

Figura 2: Jogo Super Contas 


\section{JOGOS DESENVOLVIDOS}

Com o objetivo de oferecer uma ferramenta que auxilia o processo de ensino-aprendizagem dos alunos, foram desenvolvidos diversos jogos educacionais com conteúdos de diversas disciplinas do ensino fundamental, alguns destes jogos são descritos a seguir.

Mediante as dificuldades encontradas pelos alunos em absorver os diversos conhecimentos abordados nas aulas de Ciências e a falta de recursos que possibilitasse ao professor uma interação maior entre os alunos e os conteúdos ministrados em sala, foi desenvolvido o jogo "Pelos caminhos da Ciência", que tem por objetivo auxiliar os alunos na aprendizagem e compreensão dos diversos conteúdos de Ciências, consolidando os conhecimentos adquiridos.

O jogo foi desenvolvido e elaborado para alunos do 60 ao 90 ano do ensino fundamental e tem como base a teoria construtivista, já que oferece ao aluno uma forma para que este possa construir seu próprio conhecimento por meio da busca por soluções para os problemas apresentados.

Portanto, de acordo com as dificuldades destes alunos e com o intuito de sanar essas deficiências de aprendizagem, foram pesquisadas e formuladas juntamente com os professores de uma Escola Estadual, escola esta beneficiada com o Projeto UCA, questões que envolvem os diversos temas de Ciências, tendo como auxílio pedagógico a utilização do livro didático adotado pela referida escola.

O jogo foi elaborado em forma de tabuleiro contendo 48 casas, as quais se misturam entre casas especiais compostas por questões-desafios, e casas especiais para compra de auxílios que o ajudarão a responder tais questões. Entre estes bônus estão: pulo, dica, auxílio e eliminação de alternativas. Ao responder as questões corretamente o aluno acumula pontos que servirão para comprar os auxílios descritos acima, caso caiam em alguma casa especial que possibilite isso. Em caso de erro, existirá uma punição para cada pergunta respondida de maneira errônea, o que dependerá do nível de dificuldade da pergunta:

- Para perguntas de nível fácil o aluno retornará 3 casas;

- Para perguntas de nível médio o aluno retornará 2 casas; e

- Para perguntas de nível difícil o aluno retornará 1 casa.

O banco de dados das perguntas contidas no jogo muda de acordo com a série que for utilizálo, estando a critério do professor. Ao completar o tabuleiro, o aluno atingirá uma pontuação que ficará gravada em um ranking disputado por todos os alunos que pertencerem àquele nível de ensino, havendo, porém, um ranking para todas as séries do 6 으 ao 9o ano. A tela com o tabuleiro do jogo é demonstrado na figura 3 a seguir. 


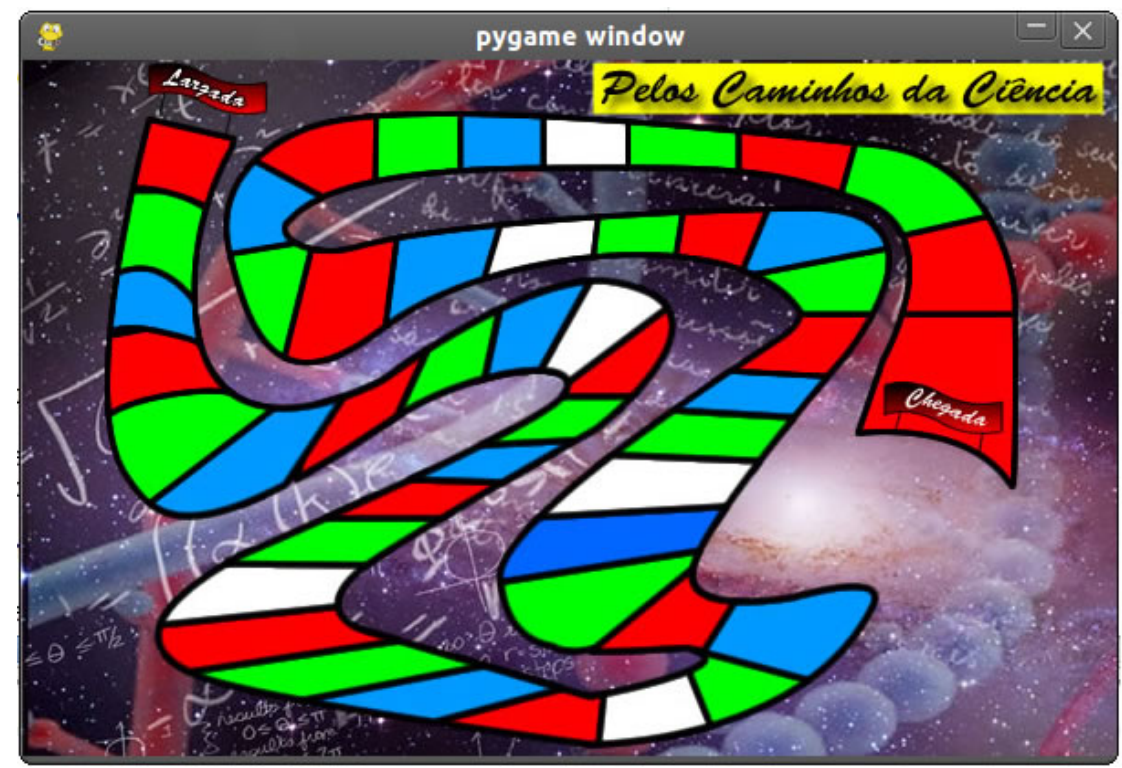

Figura 3: 0 tabuleiro do jogo

Também elaborado para auxiliar a disciplina de português do 7o ano, foi desenvolvido o jogo denominado "Classes Gramaticais", que é um jogo de concentração e interpretação, com objetivo classificar a palavra (verbo, advérbio, substantivo e pronome) de acordo com o seu tipo ou tempo verbal (no caso de um verbo). Inicialmente o jogador deve escolher e clicar em uma das quatro classes gramaticais que aparecem na tela de acordo com a Figura 4 que é ilustrada abaixo.

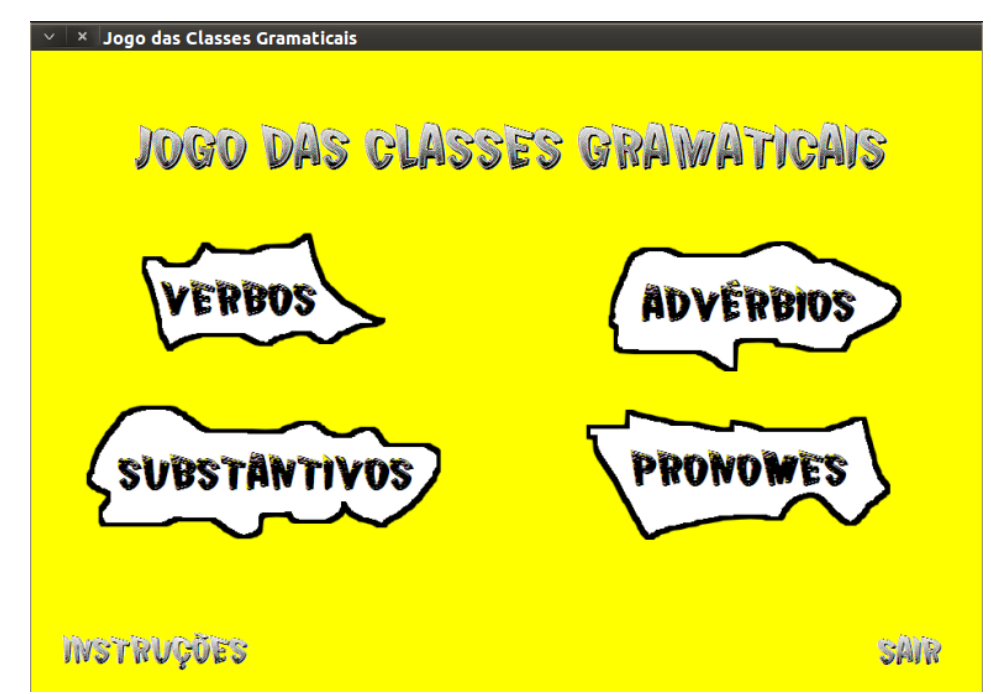

Figura 4: Jogo das Classes Gramaticais

Em seguida, o jogo é iniciado e consiste em classificar uma dada palavra que se encontra em destaque, para isso basta clicar com o mouse em uma das imagens, que aparecem em acima de cada um dos tipos na parte superior da tela do computador, arrastá-la para dentro de um círculo que se encontra próximo da palavra destacada e clicar no botão Conferir que aparece no canto inferior direito. A dificuldade do jogo aumenta de acordo com o seu nível. Quanto à pontuação, esta é 
registrada no canto superior (no centro) da tela. A Figura 5 apresenta o jogo "Classes Gramaticais" (ilustrando o momento em que o jogador escolheu a opção dos verbos).

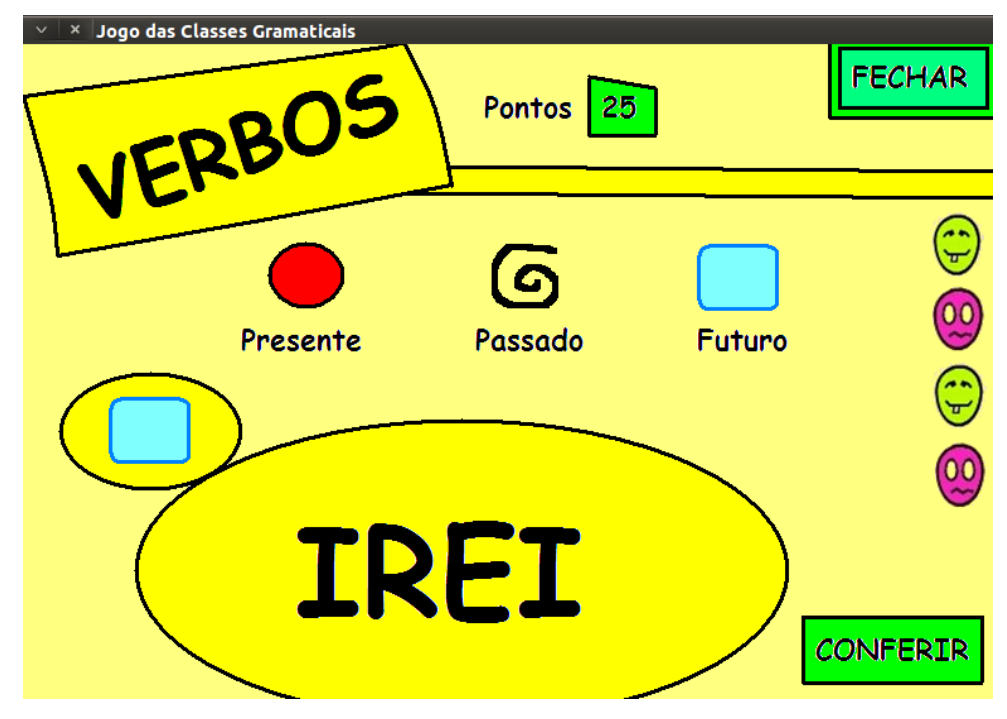

Figura 5: Opção de verbos de jogo das Classes Gramaticais

\section{RESULTADOS}

Para verificar a eficiência dos jogos educacionais, foram realizados alguns testes em sala de aula com os alunos. A metodologia adotada para verificar a eficiência do jogo e do aprendizado dos alunos é descrito a seguir.

Para a realização do teste antes da utilização dos jogos, foi distribuído um questionário contendo 15 (quinze) perguntas objetivas e 3 (três) questões subjetivas referentes aos temas do jogo, para haver uma verificação inicial sobre os conhecimentos prévios dos alunos. Em seguida, os alunos tiveram um contato inicial com o jogo para explicações gerais e sobre as regras que teriam que seguir. Depois de dar as devidas explicações o jogo foi iniciado, e o empenho e cooperação da turma diante daquele desafio foi fator primordial para que a atividade fosse realizada com sucesso. Logo após a aplicação do jogo, que durou, em um momento inicial, cerca de 50 minutos a 1 hora, foi solicitado aos alunos que respondessem novamente ao mesmo questionário, ao qual tinham preenchido inicialmente, para que houvesse assim uma avaliação dos conteúdos abordados quanto ao ganho de informações sobre determinado assunto. Ao avaliarmos o segundo questionário, foi percebido um aumento considerável na quantidade de acertos da turma.

O teste foi realizado com 30 alunos do 70 ano do ensino fundamental, que após aplicação inicial do formulário obtiveram uma média de acertos das questões objetivas de $48 \%$, após a utilização do jogo essa média subiu para 68\%. A figura 6 demonstra a média de acertos das questões objetivas antes e depois da utilização do jogo "Pelos caminhos da Ciência". 


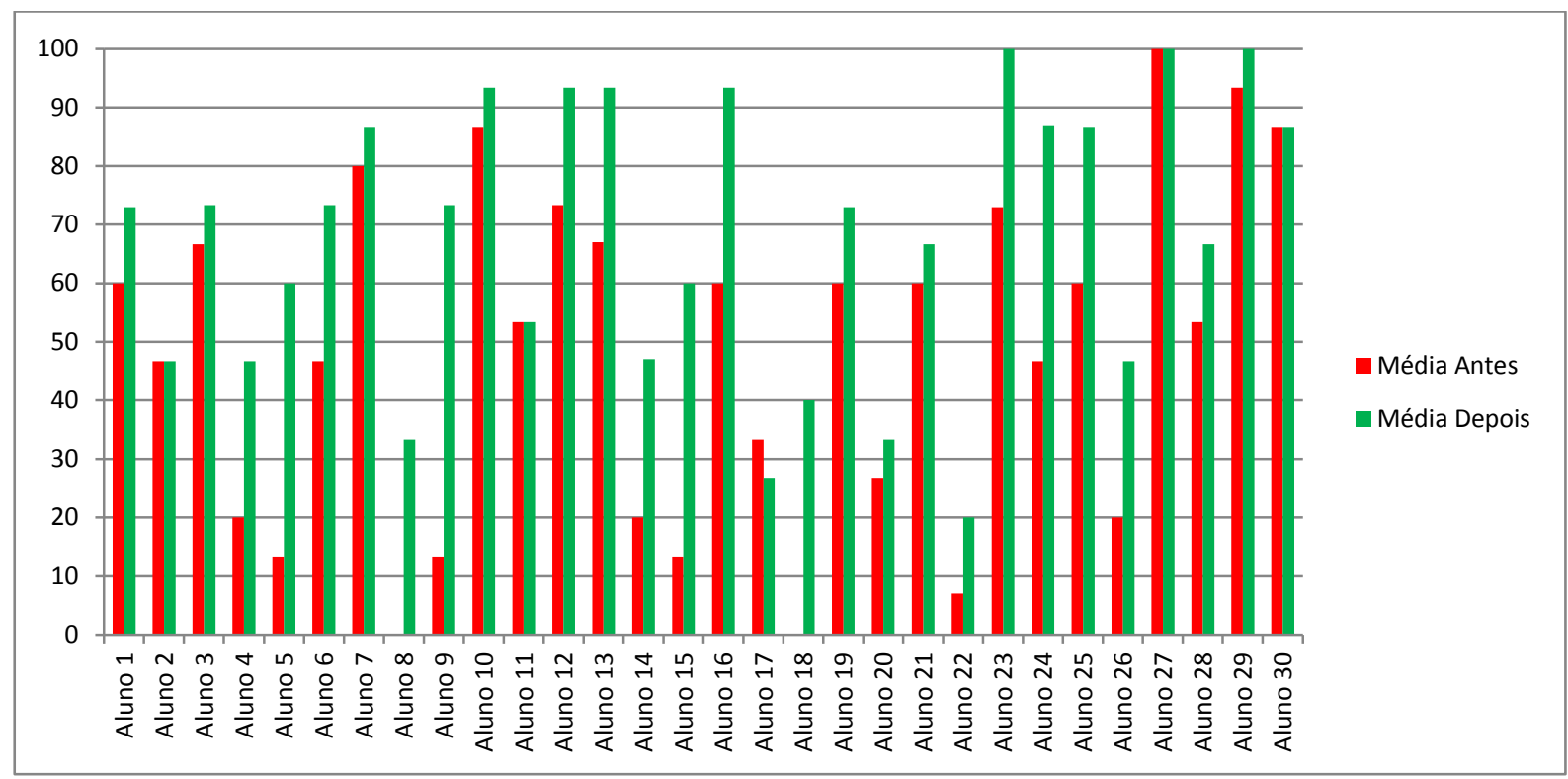

Figura 6: Gráfico com a média de acertos da turma

Ainda buscando verificar se realmente houve um ganho de conhecimento sobre os assuntos abordados, foram avaliadas as questões subjetivas para verificar se os alunos conseguiam dissertar sobre o assunto de forma mais consistente. Nesta avaliação foi percebida uma evolução das respostas dadas pelos alunos, pois no questionário inicial eles utilizaram respostas relacionadas aos seus conhecimentos prévios, enquanto que no segundo os alunos aprimoraram seus conhecimentos construindo um conceito mais consistente mediante os temas abordados.

\section{CONCLUSÕES}

Quando se possibilita aos alunos um ambiente alegre e favorável para sua aprendizagem, é notório o aumento de interesse tanto por parte dos alunos que irão sair da rotina das aulas tradicionais, como para os professores que alcançarão uma maior participação de seus alunos nas aulas, obtendo um aumento cognitivo considerável, uma vez que o processo cognitivo é contínuo e o professor deve favorecer esse processo oferecendo condições para que isto ocorra.

Com isso, diante dos resultados obtidos, concluímos que os jogos desenvolvidos propiciam aos alunos momentos de aprendizagem significativa, baseada na construção do seu próprio conhecimento, ampliando seus conceitos através de um ambiente envolto em desafios motivantes, diversão, alegria, imaginação e satisfação para encontrar as devidas soluções para os problemas que surgem no decorrer do jogo. Assim, a utilização dos jogos no apoio aos conteúdos dados em sala de aula obteve uma grande aceitação, tanto pelos alunos que absorveram os conteúdos de forma lúdica e dinâmica, quanto pelos professores que receberam com entusiasmo esta nova proposta de ferramenta metodológica para o avanço do processo ensino-aprendizagem. 


\section{AGRADECIMENTOS}

Agradecemos ao IFRN e CNPQ pelo apoio financeiro dado durante o desenvolvimento desta pesquisa.

\section{REFERÊNCIAS BIBLIOGRÁFICAS}

1. DEWEY, J. The School and Society / The Child and the Curiculum - An Expanded Edition With a New Introduction by Philip W. Jackson. The University of Chicago Press. 2000.

2. GINGER, J. One Laptop per Child - Discourse in an Information Society Context. 2009. Disponível em: http://www.communityinformaticsprojects.com/files/Cl OLPCInformationSocietyR1.pdf. Acessado em 05/07/2011.

3. GRANDO, R. C. O jogo na educação: aspectos didático-metodológicos do jogo na educação matemática. Unicamp, 2001.

4. GRÜBEL J. M., BEZ, M. Jogos Educativos. CINTED UFRGS.V.4, № 2, dezembro 2006.

5. LERNER, M. Uma Avaliação da Utilização de Jogos em Educação. Rio de Janeiro: COPPE/UFRJ, 1991. (Oficinas de Informática na Educação).

6. LIBÂNEO, JOSE CARLOS. Didática. São Paulo: Cortez, 1994.

7. LOPES, Maurício C.; WILHELM, Pedro P. H. Uso de jogos de simulação empresarial como ferramenta educacional: uma análise metodológica. XVII Simpósio Brasileiro de Informática na Educação, 2006.

8. MALFATTI, S. M., GUIMARÃES, W. B., SIMÕES, F. O, BRANCHER, J. D. Desenvolvimento de Jogos Educacionais Destinados ao Projeto UCA. Simpósio Brasileiro de Jogos e Entretenimento Digital. SBGames 2010.

9. MURCIA, J. A. M. Aprendizagem através do jogo. Porto Alegre: Artmed, 2005. 173p.

10. SEABRA, Carlos. O computador na criação de ambientes interativos de aprendizagem. Brasília, ano 12, n.57, jan./mar., 1993. p.45-50. 